University of Nebraska - Lincoln

DigitalCommons@University of Nebraska - Lincoln

Nutrition and Health Sciences -- Faculty

Publications

Nutrition and Health Sciences, Department of

2016

Food insecurity and housing instability in vulnerable families

Christian King

University of Nebraska-Lincoln, Christian.King@ucf.edu

Follow this and additional works at: https://digitalcommons.unl.edu/nutritionfacpub

Part of the Community-Based Research Commons, Family, Life Course, and Society Commons, Health Policy Commons, Human and Clinical Nutrition Commons, Medicine and Health Commons, Molecular, Genetic, and Biochemical Nutrition Commons, and the Other Nutrition Commons

King, Christian, "Food insecurity and housing instability in vulnerable families" (2016). Nutrition and Health Sciences -- Faculty Publications. 71.

https://digitalcommons.unl.edu/nutritionfacpub/71

This Article is brought to you for free and open access by the Nutrition and Health Sciences, Department of at DigitalCommons@University of Nebraska - Lincoln. It has been accepted for inclusion in Nutrition and Health Sciences -- Faculty Publications by an authorized administrator of DigitalCommons@University of Nebraska Lincoln. 


\title{
Food insecurity and housing instability in vulnerable families
}

\author{
Christian King \\ Department of Nutrition and Health Sciences, University of Nebraska-Lincoln, \\ 104I Ruth Leverton Hall, Lincoln, NE 68583, USA \\ Corresponding author _Christian King, cking7@unl.edu
}

\begin{abstract}
Reducing the prevalence of household food insecurity has been a long-standing objective of the federal government. Previous research has found many negative consequences of food insecurity for families and households but has not examined its relationship with housing instability. Using longitudinal data from the Fragile Families and Child Wellbeing Study, difference-in-difference models show that food insecurity is associated with housing instability. The association remains statistically significant after accounting for potential selection and unobserved heterogeneity using propensity score matching and excluding households that experienced prior housing instability from the sample. Examining potential mediating factors, I find that material hardship explains about half of this association. These findings suggest that maintaining a strong social safety net would reduce the risk that families experience material hardship and housing instability, which may also reduce the risk of homelessness.
\end{abstract}

Keywords: Food insecurity, Housing instability, Material hardship, Consumption, Poverty

\section{Introduction}

Food insecurity, the lack of access to enough food to maintain an active and healthy life, affects many households and families in the United States. In 2014, almost one out of six Americans-or about 50 million-is food insecure (Coleman-Jensen et al. 2015). Food insecurity leads to many negative consequences for families. For example, 
a literature review on the impact of food insecurity on health documents many negative short and long-term outcomes for children, adults, and also seniors (Gundersen and Ziliak 2015).

Reviewing the literature on the determinants of food insecurity, Gundersen and Ziliak (2014) list the following factors that increase the risk of child food insecurity: poor maternal mental health, single parenthood, drug use and abuse, unstable family structure with a non-resident father, being an immigrant, paternal incarceration, and noncenter based child care. In addition, economic hardship and low-income are also strongly correlated with household food insecurity (Coleman-Jensen et al. 2015).

Most studies on the negative consequences of food insecurity have focused on health outcomes. Few studies have examined its impacts on another type of hardship: housing instability. Housing instability, which includes missing rent or mortgage payments, doubling-up or overcrowding, moving more than once per year, having been evicted, or being homeless, is highly prevalent among low-income households, households experiencing economic hardship, and those who receive public assistance (Acs and Loprest 2004; Burgard et al. 2012; Phinney et al. 2007; Van Order and Zorn 2002; Wood and Rangarajan 2005). Housing instability has an association with several negative long-term outcomes in adults including poor physical and mental health (Burgard et al. 2012; Park et al. 2011; Ross and Squires 2011; Suglia et al. 2011). For children, housing instability can lead to poorer physical and mental health (Masten et al. 1997; Rafferty et al. 2004; Wood et al. 1990). Stable housing is an important factor contributing to the well-being of individuals and families, which facilitates access to health care services, employment, and education (Bratt 2002; Kushel et al. 2006). The negative consequences of housing instability on child health could be long-lasting and contribute to health disparities as children in poorer health lag behind their peers in physical development, educational attainment, and labor market outcomes (Oreopoulos et al. 2008).

Determining the direction of the causality between food insecurity and housing instability is not a trivial task. Studies on the relationship between food insecurity and housing instability are lacking, despite the fact that they are correlated (Kushel et al. 2006; Ma et al. 2008). A report commissioned by Feeding America, a network of food banks, shows that over half (57\%) of the 46.5 million unique clients that Feeding America serves reported having to make the difficult choice between paying for housing or food (Weinfield et al. 2014), an increase from 46\% in its 2010 report (Mabli et al. 2010). A handful of studies have examined the association between homelessness-a specific instance of housing instability - and food insecurity. Gundersen et al. (2003) used a sample of 299 families in Massachusetts to find no association between homelessness and food insecurity. Using a sample of households in Los Angeles County, Furness et al. (2004) found that a history of homelessness is associated with food insecurity. Lee and Greif (2008) used data from the National Survey of Homeless Assistance Providers and Clients (NSHAPC) and found that homeless individuals were at higher risk of experiencing food insecurity. Some limitations of these studies are their cross-sectional design and the possibility that the findings could be due to selection. 
Food insecurity has many negative consequences, hinting to three notable potential mediating factors that could explain (part or most of) the relationship between food insecurity and housing instability: (1) maternal depression, (2) experiencing material hardship, and (3) having lower levels of social support. Food insecurity is associated with maternal depression and poor mental health (Hadley and Patil 2006; Heflin et al. 2005; HuddlestonCasas et al. 2009; Whitaker et al. 2006). First, food insecurity could increase the risk of maternal depression through the accumulation of stress from experiencing food insufficiency (Heflin et al. 2005; Whitaker et al. 2006), or through multiple nutritional deficiencies such as in vitamin $\mathrm{B}_{12}$ and folate (Alpert and Fava 1997; Reynolds 2002; Tiermeier et al. 2002). In addition, maternal depression increases the risk of experiencing housing instability (Corman et al. 2016; Curtis et al. 2014). As a result, maternal depression could mediate the relationship between food insecurity and housing instability.

Second, food insecure households tend to have lower levels of social support and informal networks (Tarasuk 2001; Walker et al. 2007), which could be a result of ineffective coping strategies (Mills and Hanson 2013). Mental illness and depression reduces the instrumental and social support available to household heads (Harknett and Hartnett 2011). Households lacking social support are substantially more likely to experience housing instability and homelessness (Eyrich et al. 2003; Fertig and Reingold 2008; Lee et al. 2010). Social support could therefore mediate the relationship between food insecurity and housing instability.

Third, food insecure households are more likely to experience various forms of material hardship (e.g. did not pay utility bills on time and got disconnected) (Corcoran et al. 1999; Heflin 2006). Households experiencing material hardships are at higher risk of housing instability and homelessness (Bassuk et al. 1997; Fertig and Reingold 2008; Lee et al. 2010). For example, a household often late on paying utility bills may be more likely to be behind on subsequent rent payments, which may lead to eviction. As a result, food insecurity could have an association with housing instability through the depletion or unavailability of resources.

The diagram in Fig. 1 summarizes these potential mediators. Because this study cannot establish causality (which will be discussed further as limitations), the arrows represent associations rather than directional links. In addition, the diagram is a simplified picture. There may be additional associations between the variables shown (especially between the mediators). However, establishing all possible paths is beyond the scope of this study and not essential for its purpose, which is to test whether these factors play a mediating role.

This study uses longitudinal data from the Fragile Families and Child Wellbeing Study (FFCWS), a sample of predominantly unmarried mothers, to examine whether food insecurity has an association with housing instability. Using difference-in-difference (DiD) models, I find that food insecurity has a statistically significant association with experiencing housing instability. To address potential selection and unobserved heterogeneity due to the possibility that food insecure households are not comparable to food secure households, I estimate two additional sets of models. Propensity score matching models show that the association between food insecurity and housing 


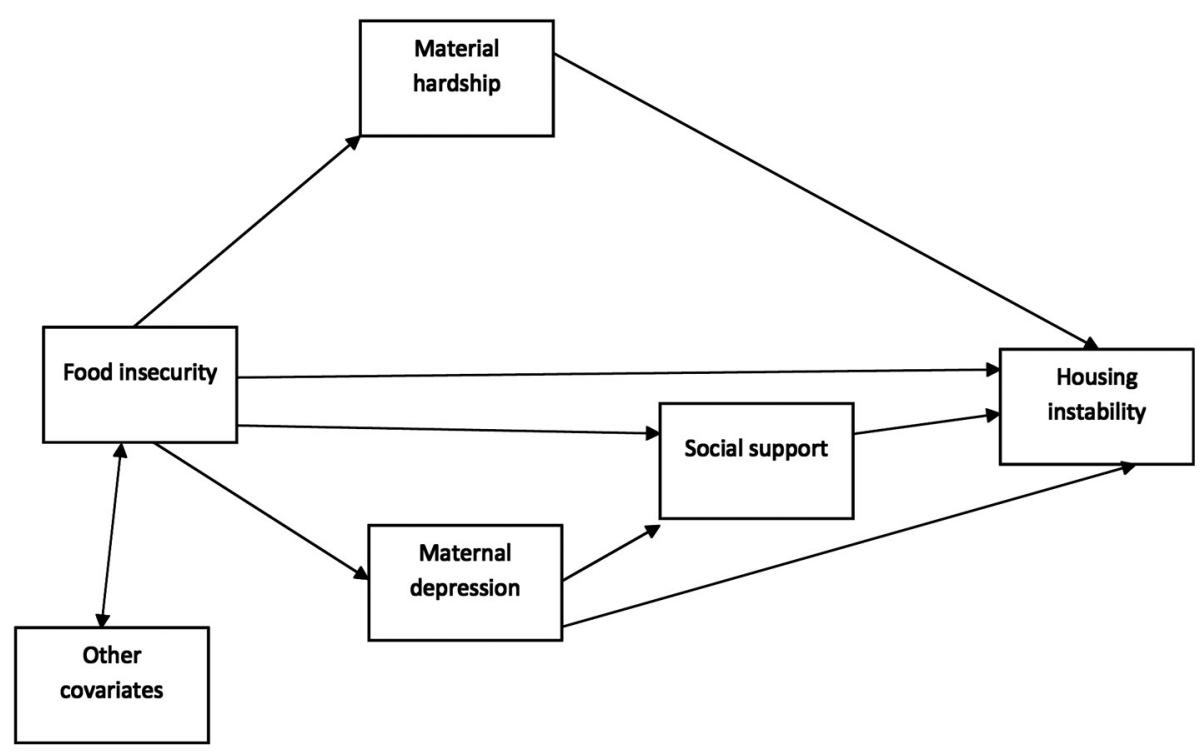

Figure 1. Diagram showing mediating factors in the relationship between food insecurity and housing instability.

instability remains statistically significant. In addition, restricting the sample to only households that did not experience prior housing instability also yielded similar results. Examining three sets of mediators, I find that material hardship and social support explain about half of this association. This indicates that food insecurity increases the risk of housing instability through a combination of material hardship and a lack of instrumental support. A stronger social safety net through public assistance programs, which are effective in reducing food insecurity (Borjas 2004; Gundersen and Ziliak 2014; Meyers et al. 2005; Ziliak 2015), would reduce material hardship and strengthen social networks and support, resulting in a lower risk of housing instability.

\section{Data}

I used data from the Fragile Families and Child Wellbeing Study (FFCWS), a longitudinal study that followed 4898 children born between 1998 and 2000 in 20 U.S. cities with populations greater than 200,000. Both parents were interviewed regularly at: baseline (birth), 1-year, 3-year, 5-year, and 9-year. By design, about three-quarters of the mothers in the sample were unmarried at baseline as the goal of the study is to focus on "fragile" families that are at higher risk of separation and living in poverty.

During each interview, parents provide extensive information about themselves and their child. This study uses the 3rd and 5th year core follow-ups as well as the corresponding in-home surveys, which includes the food insecurity questionnaire. After attrition and dropping families that did not complete all surveys, the remaining sample 
size has 2488 families. I further drop seven families that had missing values on the outcome variable to have a final sample size of 2481 .

Comparing the study sample to the one lost from attrition (Table 1), a higher proportion of mothers who remained in the sample are black (51 vs 44\%), married (30 vs $24 \%$ ), and cohabitating (20 vs $14 \%$ ). A higher proportion of mothers who dropped from the sample are Hispanic (31 vs $24 \%$ ), immigrant (23 vs $13 \%$ ), and separated from the father (59 vs 44\%). A handful of these differences are statistically significant.

A binary dependent variable defines housing instability for families who experienced one of the following living conditions in the past 12 months: (1) missed rent or mortgage payment, (2) moved-in with others (double-up), (3) moved more than once, (4) evicted, or (5) were homeless or stayed at a shelter/abandoned building/automobile (Curtis et al. 2014; Fertig and Reingold 2008; Geller and Franklin 2014). Moving-in with others, also known as doubling-up, can also serve as a safety net (Pilkauskas et al. 2014). Including doubling-up into the housing instability measure would not adequately measure housing hardship. I estimated alternative models excluding doubled-up households to ensure that the results do not change.

The Fragile Families study uses the United States Department of Agriculture (USDA) food security survey. This 18-item survey is the standard instrument used in the literature to measure food security, which the US Census Current Population Survey (CPS) also uses. Households with children answer all 18 questions while households without children answer only the first ten. The first question asks whether in the last 12 months "we worried whether our food would run out before we got money to buy more." Households with children are food insecure if they answered at least three questions affirmatively (experiencing the food related problem "almost every month" or "some months"). The module further classifies households with children answering eight or more responses affirmatively to be very low food secure. Due to its low prevalence $(\sim 3 \%)$ of in this sample, I combine both low food secure and very low food secure households in a single category.

The Fragile Families dataset has a rich set of additional explanatory variables and I include the time-variant ones in this study (Table 2).

I focus on three mediators that explain how food insecurity potentially increase the risk of housing instability: maternal depression, material hardship, and informal social support. I construct a binary measure of depression using the Composite International Diagnostic Interview Short Form (CIDI-SF) (Kessler et al. 1998). The instrument has two screeners (Table 3). If mothers answered affirmatively to either one of the two questions in the first screen, they are asked a set of seven additional questions in the second screen. The CIDI-SF considers respondents who answered affirmatively to three or more questions to be at risk of depression.

To measure material hardship, mothers are asked whether in the past year they: (1) did not pay the full amount of a gas, oil, or electricity bill, (2) someone did not see a doctor or hospital because of the cost, (3) cut back on buying clothes for themselves, (4) had the telephone disconnected, and (5) the electricity turned off. An affirmative response is 1 , otherwise is coded as 0 . I sum the number of these hardships the household experienced. Previous studies include evictions and food hardships in their measure 
Table 1. Comparison of samples by attrition status of the FFCWS data

\begin{tabular}{lrr}
\hline Variable & Remained in sample & Dropped from sample \\
\hline Mother race (\%) & 21.9 & 19.7 \\
White & 50.8 & 44.4 \\
Black & 24.0 & 30.9 \\
Hispanic & 3.3 & 5.0 \\
Other & & \\
Mother education at baseline (\%) & 32.9 & 37.2 \\
Less than high school & 30.3 & 29.3 \\
High school & 25.8 & 23.0 \\
Some college & 10.9 & 10.5 \\
College graduate or beyond & 25.2 & 25.5 \\
Mother age at baseline & 12.5 & 22.6 \\
Immigrant (\%) & 1.9 & 1.8 \\
Income to poverty ratio & & \\
Mother relationship with father (\%) & 30.0 & 24.1 \\
Married & 20.3 & 13.6 \\
Cohabitate & 5.4 & 3.7 \\
Non resident & 44.3 & 58.6 \\
Separated & 2481 & 2417 \\
Number of observations & & \\
\hline
\end{tabular}

of material hardship (Schwartz-Soicher et al. 2011; Zilanawala and Pilkauskas 2012). These items are excluded from the measure of hardship because this study tries to examine the association of food insecurity independent from other hardships and eviction is part of the housing instability outcome. To account for informal social support, mothers indicate whether they can count on someone to: (1) lend them $\$ 200$, (2) lend them $\$ 1000$, (3) provide with emergency child care, and (4) provide with a temporary place to stay. The social support measure sums these affirmative responses.

\section{Analytic strategy}

To examine the relationship between food insecurity and housing instability, I use a difference-in-difference (DiD) approach by estimating the following model using linear probability:

$$
\mathrm{HI}_{\mathrm{it}}=\beta_{0}+\beta_{1} \mathrm{FI}_{\mathrm{it}}+\beta_{2} \text { post }+\beta_{3} \mathrm{X}_{\mathrm{it}}+\eta_{t}+\mathrm{e}_{t}
$$

where $\mathrm{HI}_{\text {it }}$ indicates housing instability status for household $i$ at year $t, \mathrm{FI}_{\mathrm{it}}$ denotes food insecurity at year $t$, post denotes year $5, \mathrm{X}_{\mathrm{it}}$ denotes control variables for 
Table 2. Summary statistics by food security status of the FFCWS sample

\begin{tabular}{|c|c|c|c|}
\hline Variables & All households & Food secure & Food insecure \\
\hline Any housing instability (\%) & 22.7 & 17.3 & 41.0 \\
\hline Food insecure (\%) & 22.7 & - & - \\
\hline Mother experienced depression (\%) & 19.3 & 16.3 & 29.6 \\
\hline Material hardship (0-5) & 1.1 & 1.0 & 1.8 \\
\hline Social support (0-4) & 3.1 & 3.2 & 2.5 \\
\hline Poor maternal health (\%) & 14.2 & 11.8 & 22.4 \\
\hline Mother is employed & 57.5 & 59.3 & 51.4 \\
\hline \multicolumn{4}{|l|}{ Mother race (\%) } \\
\hline White & 21.9 & 23.7 & 16.0 \\
\hline Black & 50.8 & 49.4 & 55.4 \\
\hline Hispanic & 24.1 & 23.7 & 25.3 \\
\hline Other & 3.2 & 3.2 & 3.4 \\
\hline \multicolumn{4}{|l|}{ Mother education at baseline (\%) } \\
\hline Less than high school & 32.8 & 30.5 & 41.0 \\
\hline High school & 30.4 & 29.7 & 32.5 \\
\hline Some college & 25.8 & 26.7 & 22.9 \\
\hline College graduate or beyond & 10.9 & 13.1 & 3.4 \\
\hline Age of mother & 29.2 & 29.4 & 28.3 \\
\hline Immigrant (\%) & 12.5 & 12.6 & 12.1 \\
\hline Income to poverty ratio & 1.9 & 2.1 & 1.1 \\
\hline Number of children & 2.5 & 2.4 & 2.7 \\
\hline Mother receives housing assistance (\%) & 11.6 & 10.0 & 15.0 \\
\hline \multicolumn{4}{|l|}{ Mother relationship with father (\%) } \\
\hline Married & 29.9 & 33.6 & 17.4 \\
\hline Cohabitate & 16.7 & 16.3 & 18.2 \\
\hline Non resident & 4.4 & 3.9 & 6.2 \\
\hline Separated & 48.9 & 46.2 & 58.2 \\
\hline Mother has a new romantic partner (\%) & 23.4 & 22.1 & 28.0 \\
\hline Parental stress (1-4) & 2.2 & 2.1 & 2.5 \\
\hline Domestic violence (\%) & 4.6 & 4.0 & 6.4 \\
\hline Past drug or alcohol problems (\%) & 12.1 & 10.0 & 19.5 \\
\hline Number of observations & 2481 & 1918 & 563 \\
\hline
\end{tabular}

All differences between food secure and food insecure households are statistically significant at $p<0.01$ except for "other race."

individual $i$ at year $t$ that change over time. I also account for the clustering of observations within cities.

The strength of DiD is that all constant unobserved characteristics in the term $\eta_{\mathrm{t}}$ correlated with both food insecurity and housing instability will be differenced out. If there remain any time-variant characteristics that are associated with food insecurity and housing instability, the equation will yield biased estimates. 
Table 3. Maternal depression questionnaire

Composite International Diagnostic Interview Short Form (CIDI-SF)

First screen

In the past year, have you felt sad/depressed for 2 or more weeks in a row?

In the past year, was there a 2 week period when you lost interest in most things?

Second screen

During those 2 weeks, did you feel more tired/low on energy than usual?

Did you gain/lose weight without trying, or stay the same?

Did you have trouble falling asleep during those 2 weeks?

Did you have a lot more trouble concentrating than usual?

During this period did you feel down on yourself?

Did you think a lot about death during those 2 weeks?

In the past year, did you feel worried/tense/anxious for a month or more?

An important assumption for the DiD approach is that the pre-treatment trends are parallel, also known as common trend assumption. In this case, the assumption is difficult to verify because there are only two time periods. To ensure that the estimates are not sensitive to the choice of model, I estimate additional models.

To make the comparison groups (food secure vs food insecure households) as similar as possible, I estimate models using propensity score matching (Rosenbaum and Rubin 1983). This method is often used in observational studies where the treatment of interest was not randomly assigned to the comparison groups. More specifically, in this study, the treatment is food insecurity $\left(\mathrm{FI}_{i}\right), \mathrm{Y}_{i}(0)$ and $\mathrm{Y}_{i}(1)$ denote housing instability for household $i$ if the household is respectively food secure and food insecure, and I estimate the average treatment effect on the treated (ATET):

$$
\tau_{\mathrm{ATET}}=\mathrm{E}(\tau \mid \mathrm{D}=1)=\mathrm{E}[\mathrm{Y}(1) \mid \mathrm{D}=1]-\mathrm{E}[\mathrm{Y}(0) \mid \mathrm{D}=1]
$$

which represents the difference between the expected risk of housing instability for food secure households and the expected risk of housing instability for food insecure households.

An important assumption of propensity score matching is the Conditional Independence Assumption (CIA), which states that conditional on the covariates X, the likelihood of receiving the treatment does not change the outcome. Propensity score matching is a nonparametric method that uses a discrete choice model (typically logit or probit) to calculate the probability of receiving the treatment, matches observations based on the propensity score, and calculates the difference in outcomes between matched observations in the untreated and treated groups. Different matching methods pose a trade-off between bias and variance depending on the number of observations being discarded from the analysis. I use several matching methods and test the covariate balance.

One weakness of propensity score matching is the potential selection on unobservables. For example, households that experienced prior housing instability may be more 
likely to experience food insecurity. Also, these households are more likely to experience housing instability in the following time period. If that is the case, then food secure households would not be an adequate comparison group. To deal with this potential issue, I re-estimate Equation (1) excluding all households that experienced housing instability prior to year 3 from the sample.

I then estimate three potential mediating factors that may explain the association between food insecurity and housing instability: (1) material hardship, (2) maternal depression, and (3) social support. I use the model in Equation (1) as baseline and then estimate separate models introducing each mediator to see how the coefficient of the difference-in-difference estimate changes. I also estimate a model that includes all mediators. Finally, I include a mediation analysis using structural equation modeling to conduct an inferential test and also determine how much of the association can be explained by each mediator.

A number of variables in this study have missing values. I follow three strategies to deal with missing values. First, I keep only the complete observations. Second, I recode the missing values as dummy variables. Third, I impute missing values on the independent variables using multiple imputed chained equations (Royston 2004; 2005; von Hippel 2007). Because the results were not sensitive to the method of handling the missing data used, I report only the results from multiple imputed chained equations.

\section{Results}

\subsection{Descriptive statistics}

Table 2 presents descriptive statistics with summary statistics presented for the whole sample in the first column. Of the total sample of 2481 households with food insecurity information, about $22.7 \%$ experienced housing instability. The overall household food insecurity rate was $22.7 \%$, including $3 \%$ for very low food secure. Years 3 and 5 of the study spans years 2001 through 2003. Rates of food insecurity nationally hovered around 11\% during these years and climbed to 14\% between 2008 and 2014 (ColemanJensen et al. 2015). The proportion of food insecure households in the FFCWS data is twice as large as the national estimates because when weighted the sample is representative of non-marital births in large US cities. By design, the Fragile Families study focuses on children born to unwed parents, which are more vulnerable populations than the ones in other longitudinal studies such as the Panel Study of Income Dynamics (PSID) or the Survey of Income and Program Participation (SIPP).

About one out of five mothers (19.3\%) in this sample met the criterion of being depressed. More than two-thirds (69.1\%) of mothers were unmarried, reflecting the sampling design of the study. Because of this oversampling, a large proportion of mothers in this sample are of lower socioeconomic status. Three-quarters of mothers (74.9\%) in the sample are from a racial minority (black or Hispanic). About two-thirds have a high school degree or less (63.2\%). The average household income in this sample is 
about twice the poverty level. Close to a quarter $(23.4 \%)$ of mothers are re-partnered with someone other than the father.

The remaining table presents descriptive statistics by food security status. Food insecure mothers are at greater disadvantage than other mothers. They are more likely to have experienced housing instability (41 vs 17.3\%), more likely to be Black or Hispanic ( 80.7 vs $73.1 \%$ ), and have at most a high school degree (73.5 vs $60.3 \%$ ). Their income tends to hover around the poverty level (1.1 vs 2.1 ), and they are more likely to receive housing assistance (15 vs 10\%). Finally, food insecure mothers are less likely to have social support, greater material hardship, less likely to be employed, less stable relationships with the father, and more likely to have had a history of alcohol or drug abuse.

\subsection{Empirical results}

Table 4 presents difference-in-difference estimates of the relationship between food insecurity and housing instability. The models include clustered standard errors at the city level. The first model shows a linear probability model that includes food insecurity. Food insecurity has a statistically significant association with housing instability. In the second model, including the covariates does not change the statistical significance of food insecurity. Poor health is a risk factor in experiencing housing instability.

Since there is unclear consensus on how to use propensity score matching with multiple imputation, I present the covariate balance (Table 5) and estimates (Table 6) on the non-imputed sample. The first column shows the differences between the treated and untreated group for the unmatched sample. The table also shows the average of the standardized differences and the number of observations on and off support. The off support observations are discarded for having poor or no matches. A standardized difference of 20 is considered to be large (Lee 2013; Rosenbaum and Rubin 1985). This means that the unmatched sample has large differences between the treated and untreated group and a simple comparison between the two may be inadequate. The remaining columns show the covariate balance for various matching methods: nearest neighbor, nearest neighbor with caliper, Mahalanobis, and Kernel. The average standardized difference decreases substantially in all matching methods. Both nearest neighbor with caliper and Mahalanobis discard a large number of observations. Kernel matching calculates a weighted average of multiple observations in the untreated group for each treated observation (Heckman et al. 1997; 1998). Kernel matching reduces the average standardized difference to 2.1 and discards a minimal number of observations, making it the most optimal matching method.

Table 6 shows the average treatment on the treated (ATT) for each matching method. For the unmatched sample, the ATT is large and statistically significant. Matching substantially reduces the size of the ATT, which is statistically insignificant for nearest neighbor with caliper and Mahalanobis but these methods discard a large number of observations. For both nearest neighbor and Kernel, the ATT is 0.09 and statistically significant. This means that food insecure households are about nine percentage point more likely to experience housing instability. 
Table 4. Estimates from difference-in-difference model of food insecurity on housing instability

\begin{tabular}{|c|c|c|}
\hline & Model 1 & Model 2 \\
\hline Food insecure & $0.05^{*}(0.023)$ & $0.07 *(0.026)$ \\
\hline Age of mother & & $0.00 \quad(0.004)$ \\
\hline Income to poverty ratio & & $-0.01 \quad(0.005)$ \\
\hline \multicolumn{3}{|l|}{ Mother relationship with father } \\
\hline Married & & $-0.03 \quad(0.057)$ \\
\hline Cohabitating & & $-0.01 \quad(0.036)$ \\
\hline Separated & & $0.01 \quad(0.046)$ \\
\hline Mother has new romantic partner & & $0.04 \quad(0.031)$ \\
\hline Number of children & & $0.01 \quad(0.020)$ \\
\hline Parenting stress & & $0.02 \quad(0.014)$ \\
\hline Domestic violence & & $0.05 \quad(0.045)$ \\
\hline Drug or alcohol abuse & & $0.00 \quad(0.037)$ \\
\hline Poor health & & $0.06^{*}(0.025)$ \\
\hline Mother is employed & & $0.00 \quad(0.011)$ \\
\hline Receives public housing assistance & & $0.01 \quad(0.024)$ \\
\hline Observations & 2481 & 2481 \\
\hline \multicolumn{3}{|c|}{$\begin{array}{l}\text { Standard errors adjusted for city level clusters are in parentheses } \\
* * \text { Significant at } 1 \%\end{array}$} \\
\hline * significant at 5\% & & \\
\hline
\end{tabular}

If any hidden bias remain due to selection on unobservables, I estimate models restricting the sample to only households that did not experience any housing instability prior to year 3 (Table 7). The coefficient of food insecurity remains statistically significant. This suggests that the association between food insecurity and housing instability in this study is unlikely to be a result of selection.

I examine potential mediating factors through which this relationship operates in Table 8. The first model is the baseline model (Model 2 from Table 3). I then estimate the same model including each mediator separately in Models 2 through 4 . Model 2 suggests that material hardship explains a large proportion of the variation in the interaction term, which becomes statistically insignificant. Model 3 indicates that maternal depression does not explain much of the variation in the association. Model 4, however, suggests that controlling for social support reduces the size of the coefficient of the interaction term. Including all mediators in Model 5 shows that the size of the coefficient of food insecurity (or direct effect) is statistically insignificant. 
Table 5. Balance test on covariates after propensity score matching

\begin{tabular}{|c|c|c|c|c|c|}
\hline \multicolumn{2}{|c|}{$\begin{array}{r}\text { Full sample } \\
\text { unmatched }\end{array}$} & \multirow{2}{*}{$\begin{array}{r}\text { Nearest } \\
\text { neighbor } \\
5.0\end{array}$} & \multirow{2}{*}{$\begin{array}{r}\begin{array}{r}\text { Nearest } \\
\text { neighbor } \\
\text { with calipers }\end{array} \\
3.0\end{array}$} & \multirow{2}{*}{$\begin{array}{r}\text { Mahalanobis } \\
\text { with } \\
\text { calipers }\end{array}$} & \multirow{2}{*}{$\begin{array}{r}\text { Kernel } \\
-0.6\end{array}$} \\
\hline Mother HS degree & 8.3 & & & & \\
\hline Mother some college & -4.5 & 1.6 & -3.9 & 0 & 2.3 \\
\hline Mother has college degree & -43.8 & -2.5 & -4.1 & 0 & 1.7 \\
\hline Mother is black & 19.8 & -1.9 & -1.7 & 0 & -3.7 \\
\hline Mother is hispanic & -0.1 & 0 & -3.9 & 0 & 1.9 \\
\hline Mother other race & 0.9 & 8.9 & 3.1 & 0 & 3.3 \\
\hline Mother age & -11.9 & -0.5 & -4.8 & 6.3 & 1.6 \\
\hline Mother is married & -44.5 & 0.5 & 0.6 & 0 & .0 \\
\hline Mother is cohabitating & 2.9 & 4.6 & 4.8 & 0 & -1.1 \\
\hline Mother is separated & 31.5 & -4.2 & -1.7 & 0 & -1.3 \\
\hline $\begin{array}{l}\text { Mother has new romantic } \\
\text { partner }\end{array}$ & 17.1 & 0.5 & 2.6 & 0 & 2.8 \\
\hline Number of children & 23.2 & -1.8 & 4.6 & 4.5 & -8.8 \\
\hline Parenting stress & 41.2 & 4.8 & 7.7 & 4.4 & 2.6 \\
\hline Domestic violence & 3.7 & 2.7 & -3.2 & 0 & 0.6 \\
\hline Drug or alcohol abuse & 33.0 & 1.2 & 1.5 & 0 & 2.9 \\
\hline Income to poverty ratio & -55.0 & 1.7 & -0.3 & -2.2 & 0.5 \\
\hline Receives housing assistance & 15.1 & 1.7 & 2.1 & 0 & 0.4 \\
\hline Social support & -61.7 & -8.4 & -13.7 & 0 & 0.6 \\
\hline Employed & -15.7 & 1.4 & -8.6 & 0 & 1.9 \\
\hline Material hardship & 86.3 & -6.5 & -9.2 & 0 & -1.6 \\
\hline Maternal depression & 37.1 & 1.1 & 3.5 & 0 & 2.8 \\
\hline Poor maternal health & 32.1 & -5.4 & -5.1 & 0 & 1.4 \\
\hline Average difference & 21.5 & 3.0 & 4.3 & 0.8 & 2.1 \\
\hline \multicolumn{6}{|l|}{ Observations } \\
\hline On support & 2481 & 2096 & 1383 & 35 & 2014 \\
\hline Off support & & & 713 (78) & $2061(416)$ & $82(15)$ \\
\hline
\end{tabular}

The numbers in the table are standardized difference of means.

The numbers in parentheses for off support indicates the number of treated observations that were discarded. 
Table 6. Average Treatment on the treated

Method ATT

$\begin{array}{ll}\text { Without matching } & 0.27^{* *} \\ \text { Nearest neighbor } & 0.09^{*} \\ \text { Nearest neighbor with caliper } & 0.05 \\ \text { Mahalanobis } & 0.19 \\ \text { Kernel } & 0.09^{* *}\end{array}$

** Significant at $1 \%$;

* significant at $5 \%$

Table 7. Estimates from difference-in-difference model of food insecurity on housing instability excluding all households that previously experienced housing instability

\begin{tabular}{lcc}
\hline & Model 1 & Model 2 \\
\hline Food insecure & $0.06^{*}(0.026)$ & $0.08^{* *}(0.026)$ \\
Age of mother & $0.01(0.001)$ \\
Income to poverty ratio & $-0.01^{*}(0.004)$ \\
Mother relationship with father & & \\
Married & $-0.08(0.065)$ \\
Cohabitating & $-0.06(0.057)$ \\
Separated & $-0.07(0.062)$ \\
Mother has new romantic partner & $0.01(0.038)$ \\
Number of children & $0.00(0.018)$ \\
Parenting stress & $0.02(0.019)$ \\
Domestic violence & $0.13(0.066)$ \\
Drug or alcohol abuse & $0.10^{*}(0.048)$ \\
Poor health & $0.03(0.030)$ \\
Mother is employed & $0.02(0.015)$ \\
Receives public housing assistance & $0.03 \quad(0.026)$ \\
Observations & 1803 & 1803 \\
\hline
\end{tabular}

Standard errors adjusted for city level clusters are in parentheses.

** Significant at $1 \%$;

* significant at $5 \%$ 
Table 8 Estimates from difference-in-difference model of food insecurity on housing instability including mediating factors

\begin{tabular}{llllll}
\hline & Model 1 & Model 2 & Model 3 & Model 4 & Model 5 \\
\hline Food insecure & $0.07^{* *}$ & 0.04 & $0.06^{*}$ & 0.04 & 0.01 \\
& $(0.026)$ & $(0.025)$ & $(0.026)$ & $(0.025)$ & $(0.025)$ \\
Material hardship & & $0.08^{* *}$ & & & $0.08^{* *}$ \\
Maternal depression & & $(0.008)$ & & & $(0.010)$ \\
Social support & & $0.10^{* *}$ & & $0.08^{* *}$ \\
& & & $(0.028)$ & & $(0.030)$ \\
Observations & 2481 & 2481 & 2481 & $-0.03^{* *}$ & -0.03 \\
\hline
\end{tabular}

Standard errors adjusted for city level clusters are in parentheses.

$* * p<0.01 ; * p<0.05$

To test for mediation, additional models need to be estimated to produce the total, direct, and indirect effects of food insecurity. The total effect is the coefficient of food insecurity when the mediators are excluded. The direct effect is the coefficient of food insecurity in the full model that includes mediators and covariates. The indirect effect needs to be calculated when there are more than one mediator. When using cross-sectional models, these estimates can be recovered through simple regression analysis (Hayes 2013). Because this study uses longitudinal data, it is recommended to use methods such as structural equation modeling (Cole and Maxwell 2003; MacKinnon et al. 2007).

Table 9 provides the estimates of the mediation analysis using structural equation modeling. The models were estimated on the non-imputed data. The indirect effect of food insecurity through the three mediators accounts for $55 \%$ of the association between food insecurity and housing instability (0.098/0.178). Most of the mediation comes from

Table 9 Mediation analysis using structural equation modeling

\begin{tabular}{llll}
\hline Path & $\begin{array}{l}\text { Estimate }(\% \\
\text { mediated) }\end{array}$ & $\begin{array}{l}\text { Confidence } \\
\text { interval }\end{array}$ & $\begin{array}{l}\text { Confidence interval } \\
\text { (bias corrected) }\end{array}$ \\
\hline $\begin{array}{l}\text { Food insecurity } \\
\quad \text { Total effect }\end{array}$ & $0.178^{* *}$ & $0.148-0.208$ & $0.140-0.213$ \\
$\quad$ Direct effect & $0.080^{* *}$ & $0.050-0.109$ & $0.043-0.117$ \\
$\quad$ Indirect effect & $0.098^{* *}$ & $0.085-0.112$ & $0.083-0.114$ \\
Indirect effect through & & & \\
$\quad$ Material hardship & $0.087^{* *}(49 \%)$ & $0.070-0.105$ & \\
$\quad$ Maternal depression & $0.003^{* *}(1.7 \%)$ & $0.000-0.007$ & \\
Social support & $0.009^{* *}(5.1 \%)$ & $0.003-0.016$ & \\
\hline
\end{tabular}

${ }^{* *} p<0.01 ; * p<0.05$. Proportion mediated in parentheses. Confidence intervals for effects of food insecurity are bias corrected 
material hardship, which accounts for $89 \%$ of the indirect effect and $49 \%$ of the total effect of food insecurity. To conduct an inferential test of the total indirect effect, bootstrap confidence intervals are used because the sampling distribution may not be normal, which may yield incorrect confidence intervals (Hayes 2013). I used 5000 bootstrap resamples to calculate $95 \%$ bias-corrected confidence intervals, which are slightly wider than the uncorrected ones. All the effects (total, direct, and indirect) remain statistically significant. Taken together, these findings suggest that material hardship is the primary mediator linking food insecurity and housing instability.

\section{Discussion}

Reducing the prevalence of household food insecurity has been an objective of the federal government for the last few decades and also listed in the Healthy People Initiatives of 2010 and 2020. While the literature has found many negative consequences of food insecurity, few studies have examined its relationship with housing instability. Using data from the Fragile Families and Child Wellbeing Study (FFCWS), difference-in-difference models show a statistically significant association between food insecurity and housing instability. This association remained statistically significant after accounting for potential selection using propensity score matching and excluding household that previously experienced housing instability from the sample. In addition, the mediation analysis suggests that material hardship makes food insecure households at greater risk of experiencing housing instability.

The analysis has some limitations. First, this study does not address causality as it cannot rule out the possibility of reverse causality between food insecurity and housing instability. In addition, the difference-in-difference models do not address any potential bias due to time-varying unobservable factors correlated with both food insecurity and housing instability. Second, while the housing instability measure captures a wide range of living conditions, I cannot measure the frequency at which mothers experienced unstable housing. For example, mothers who experience repeated episodes of housing instability would likely be worse off than mothers who experience unstable housing only once and the analysis cannot distinguish between the two. Third, the sample in the Fragile Families and Child Wellbeing Study is representative of non-marital births in 20 large U.S. cities when weighted. As a result, the generalizability of these findings to other populations is unclear.

Despite those limitations, the findings have potential implications for policy. Maintaining and strengthening the social safety net would reduce these risks factors contributing to housing instability. Although household food insecurity rates have plateaued at around $14 \%$ for the last several years, enrollments in the Supplemental Nutrition Assistance Program (SNAP), however, have steadily increased and were at an all-time high until 2013. Ziliak (2015) reports that one out of seven American received benefits from the program at a total cost of $\$ 80$ billion in 2013, making it the second largest public assistance program after Medicaid. He argues that weak macroeconomic factors consisting of a combination of a high unemployment, low-incomes, and income inequality 
have contributed to the explosion of food stamps enrollment. Consequently, cuts in the program, through budget decreases or termination of eligibility, before the economy recovers would lead to families experience even greater hardships. Examining the effectiveness of SNAP, Kreider et al. (2012) argue that findings from previous studies of deleterious impacts of the SNAP program on health are driven by the endogeneity and misreporting of SNAP participation. Using a partial identification bounding methods, they find that the program at least alleviates food security and poor health outcomes.

Aside from SNAP, other programs targeted to improve food security would also reduce material hardship. Examples of such programs are school meals programs through the School Breakfast Program (SBP) and National School Lunch Program (NSLP), and the Special Supplemental Nutrition Program for Women, Infants, and Children (WIC). Reviewing the literature on the causal effects of these programs, Gundersen and Ziliak (2014) conclude that the most credible evaluations of these programs show evidence of their effectiveness in reducing child food insecurity. These programs should also improve the food security of parents since the programs free up resources that would be spent on providing nutrition to children. In addition, improving parental food security would improve their health, improve their ability to maintain employment, and potentially lead to stronger social network they could use when needed.

For policymakers, comparing between food insecurity and housing instability (or even homelessness), addressing food insecurity might be the least difficult issue to tackle. The supply of adequate and affordable housing tends to be in greater shortage compared to food. In addition, providing housing or subsidies towards it might be costlier than providing food subsidies, such as through the Supplemental Nutrition Assistance Program (and other public assistance programs). Similar to preventive health care services, improving household food security may be more efficient and cost-effective than providing housing assistance once these households experience housing instability. Given that housing instability has long term negative consequences on mothers and children, strengthening the social safety net could break the near endless cycle of maternal and family poverty, reduce social inequality, and improve the educational attainment of children.

Acknowledgments - I would like to thank Greg Lewis and Sara Markowitz for their helpful comments and suggestions on an early draft. I am very grateful for comments and suggestions provided by two anonymous reviewers and the co-editor (Prof. George Davis), which greatly improved the version originally submitted. Access to the contract data was provided by the Bendheim-Thoman Center for Research on Child Wellbeing at Princeton University. The Fragile Families and Child Wellbeing Study was funded by Grant R01 HD36916 from the Eunice Kennedy Shriver National Institute of Child Health and Human Development (NICHD) and a consortium of private foundations. 


\section{References}

Acs, G., \& Loprest, P. (2004). Leaving welfare: Employment and well-being of families that left welfare in the post-entitlement era. Kalamazoo, MI: W.E. Upjohn Institute for Employment Research.

Alpert, J. E., \& Fava, M. (1997). Nutrition and depression: The role of folate. Nutrition Reviews, 55(5), $145-149$.

Bassuk, E. L., Buckner, J. C., Weinreb, L. F., Browne, A., Bassuk, S. S., Dawson, R., \& Perloff, J. N. (1997). Homelessness in female-headed families: Childhood and adult risk and protective factors. American Journal of Public Health, 87(2), 241-248.

Borjas, G. J. (2004). Food insecurity and public assistance. Journal of Public Economics, 88(7-8), 1421-1443.

Bratt, R. G. (2002). Housing and family well-being. Housing Studies, 17(1), 13-26.

Burgard, S. A., Seefeldt, K. S., \& Zelner, S. (2012). Housing instability and health: Findings from the Michigan recession and recovery study. Social Science and Medicine, 75(12), 2215-2224.

Cole, D. A., \& Maxwell, S. E. (2003). Testing mediational models with longitudinal data: Questions and tips in the use of structural equation modeling. Journal of Abnormal Psychology, 112(4), 558-577.

Coleman-Jensen, A., Nord, M., \& Singh, A. (2015). Household food security in the United States in 2014. USDA Economic Research Report No 194. Washington, DC.

Corcoran, M. E., Heflin, C. M., \& Siefert, K. (1999). Food insufficiency and material hardship in postTANF welfare families. Ohio St. Law Journal, 60, 1395-1422.

Corman, H., Curtis, M. A., Noonan, K., \& Reichman, N. E. (2016). Maternal depression as a risk factor for children's inadequate housing conditions. Social Science and Medicine, 149, 76-83.

Curtis, M., Corman, H., Noonan, K., \& Reichman, N. (2014). Maternal depression as a risk factor for family homelessness. American Journal of Public Health, 104(9), 1664-1670.

Eyrich, K. M., Pollio, D. E., \& North, C. S. (2003). An exploration of alienation and replacement theories of social support in homelessness. Social Work Research, 27(4), 222-231.

Fertig, A. R., \& Reingold, D. A. (2008). Homelessness among at risk families with children in twenty American cities. Social Service Review, 82(3), 485-510.

Furness, B. W., Simon, P. A., Wold, C. M., \& Asarian-Anderson, J. (2004). Prevalence and predictors of food insecurity among low-income households in Los Angeles County. Public Health Nutrition, 7(06), 791-794.

Geller, A., \& Franklin, A. W. (2014). Paternal incarceration and the housing security of urban mothers. Journal of Marriage and Family, 76(2), 411-427.

Gundersen, C., Weinreb, L., Wehler, C., \& Hosmer, D. (2003). Homelessness and food insecurity. Journal of Housing Economics, 12(3), 250-272.

Gundersen, C., \& Ziliak, J. P. (2014). Childhood food insecurity in the U.S.: Trends, causes, and policy options. The Future of Children, 24(2), 1-19.

Gundersen, C., \& Ziliak, J. P. (2015). Food insecurity and health outcomes. Health Affairs, 34(11), 1830-1839.

Hadley, C., \& Patil, C. L. (2006). Food insecurity in rural Tanzania is associated with maternal anxiety and depression. American Journal of Human Biology, 18(3), 359-368.

Harknett, K. S., \& Hartnett, C. S. (2011). Who lacks support and why? An examination of mothers' personal safety nets. Journal of Marriage and Family, 73(4), 861-875.

Hayes, A. F. (2013). Introduction to mediation, moderation, and conditional process analysis: A regression-based approach. New York, NY: Guilford Press.

Heckman, J. J., Ichimura, H., \& Todd, P. E. (1997). Matching as an econometric evaluation estimator: Evidence from evaluating a job training programme. The Review of Economic Studies, 64(4), $605-654$. 
Heckman, J. J., Ichimura, H., \& Todd, P. (1998). Matching as an econometric evaluation estimator. The Review of Economic Studies, 65(2), 261-294.

Heflin, C. (2006). Dynamics of material hardship in the women's employment study. Social Service Review, 80(3), 377-397.

Heflin, C. M., Siefert, K., \& Williams, D. R. (2005). Food insufficiency and women's mental health: Findings from a 3-year panel of welfare recipients. Social Science and Medicine, 61(9), 1971-1982.

Huddleston-Casas, C., Charnigo, R., \& Simmons, L. A. (2009). Food insecurity and maternal depression in rural, low-income families: A longitudinal investigation. Public Health Nutrition, 12(08), 1133-1140.

Kessler, R. C., Andrews, G., Mroczek, D., Ustun, B., \& Wittchen, H.-U. (1998). The World Health Organization composite international diagnostic interview short-form (CIDI-SF). International Journal of Methods in Psychiatric Research, 7(4), 171-185.

Kreider, B., Pepper, J. V., Gundersen, C., \& Jolliffe, D. (2012). Identifying the effects of SNAP (food stamps) on child health outcomes when participation is endogenous and misreported. Journal of the American Statistical Association, 107(499), 958-975.

Kushel, M. B., Gupta, R., Gee, L., \& Haas, J. S. (2006). Housing instability and food insecurity as barriers to health care among low-income Americans. Journal of General Internal Medicine, 21(1), 71-77.

Lee, W.-S. (2013). Propensity score matching and variations on the balancing test. Empirical Economics, 44(1), 47-80.

Lee, B. A., \& Greif, M. J. (2008). Homelessness and hunger. Journal of Health and Social Behavior, $49(1), 3-19$.

Lee, B. A., Tyler, K. A., \& Wright, J. D. (2010). The new homelessness revisited. Annual review of sociology, 36, 501-521.

Ma, C. T., Gee, L., \& Kushel, M. B. (2008). Associations between housing instability and food insecurity with health care access in low-income children. Ambulatory Pediatrics, 8(1), 50-57.

Mabli, J., Cohen, R., Potter, F., \& Zhao, Z. (2010). Hunger in America 2010 National report prepared for feeding America. Princeton, NJ: Mathematica Policy Research.

MacKinnon, D. P., Fairchild, A. J., \& Fritz, M. S. (2007). Mediation analysis. Annual Review of Psychology, 58,593 .

Masten, A. S., Sesma, A, Jr., Si-Asar, R., Lawrence, C., Miliotis, D., \& Dionne, J. A. (1997). Educational risks for children experiencing homelessness. Journal of School Psychology, 35(1), 27-46.

Meyers, A., Cutts, D., Frank, D. A., et al. (2005). Subsidized housing and children's nutritional status: Data from a multisite surveillance study. Archives of Pediatrics and Adolescent Medicine, 159(6), $551-556$.

Mills, G., \& Hanson, K. (2013). Coping strategies for households at risk of childhood hunger: Final Report submitted to the University of Kentucky Center for Poverty Research. Washington, DC: The Urban Institute.

Oreopoulos, P., Stabile, M., Walld, R., \& Roos, L. L. (2008). Short-, medium-, and long-term consequences of poor infant health: An Analysis using siblings and twins. Journal of Human Resources, 43(1), 88-138.

Park, J. M., Fertig, A. R., \& Metraux, S. (2011). Changes in maternal health and health behaviors as a function of homelessness. Social Service Review, 85(4), 565-585.

Phinney, R., Danziger, S., Pollack, H. A., \& Seefeldt, K. S. (2007). Housing instability among current and former welfare recipients. American Journal of Public Health, 97(5), 832-837.

Pilkauskas, N. V., Garfinkel, I., \& McLanahan, S. (2014). The prevalence and economic value of doubling up. Demography, 51, 1667-1676.

Rafferty, Y., Shinn, M., \& Weitzman, B. C. (2004). Academic achievement among formerly homeless adolescents and their continuously housed peers. Journal of School Psychology, 42(3), 179-199. 
Reynolds, E. H. (2002). Folic acid, ageing, depression, and dementia. BMJ, 324(7352), 1512-1515.

Rosenbaum, P. R., \& Rubin, D. B. (1983). The central role of the propensity score in observational studies for causal effects. Biometrika, 70(1), 41-55.

Rosenbaum, P. R., \& Rubin, D. B. (1985). Constructing a control group using multivariate matched sampling methods that incorporate the propensity score. The American Statistician, 39(1), 33-38.

Ross, L. M., \& Squires, G. D. (2011). The personal costs of subprime lending and the foreclosure crisis: A matter of trust, insecurity, and institutional deception. Social Science Quarterly, 92(1), 140-163.

Royston, P. (2004). Multiple imputation of missing values. The Stata Journal, 4(3), 227-241.

Royston, P. (2005). Multiple imputation of missing values: Update of ice. The Stata Journal, 5(4), $527-536$.

Schwartz-Soicher, O., Geller, A., \& Garfinkel, I. (2011). The effect of paternal incarceration on material hardship. Social Service Review, 85(3), 447-473.

Suglia, S., Duarte, C., \& Sandel, M. (2011). Housing quality, housing instability, and maternal mental health. Journal of Urban Health, 88(6), 1105-1116.

Tarasuk, V. S. (2001). Household food insecurity with hunger is associated with women's food intakes, health and household circumstances. The Journal of Nutrition, 131(10), 2670-2676.

Tiermeier, H., van Tuijl, H. R., Hofman, A., Meijer, J., Kiliaan, A., \& Breteler, M. M. B. (2002). Vitamin B12, Folate, and Homocysteine in Depression: The Rotterdam Study. The American Journal of Psychiatry, 159, 2099-2101.

Van Order, R., \& Zorn, P. (2002). Performance of low-income and minority mortgages. In N. P. Retsinas \& E. S. Belsky (Eds.), Washington. DC: Brookings Institution Press.

Von Hippel, P. T. (2007). Regression with missing Ys: An improved strategy for analyzing multiply imputed data. Sociological Methodology, 37(1), 83-117.

Walker, J. L., Holben, D. H., Kropf, M. L., Holcomb, J. P, Jr, \& Anderson, H. (2007). Household food insecurity is inversely associated with social capital and health in females from special supplemental nutrition program for women, infants, and children households in Appalachian Ohio. Journal of the American Dietetic Association, 107(11), 1989-1993.

Weinfield, N. S., Mills, G., Borger, C., Gearing, M., Macaluso, T., Montaquila, J., \& Zedlewski, S. (2014). Hunger in America 2014. Westat and the Urban Institute: National report prepared for Feeding America.

Whitaker, R. C., Phillips, S. M., \& Orzol, S. M. (2006). Food insecurity and the risks of depression and anxiety in mothers and behavior problems in their preschool-aged children. Pediatrics, 118(3), e859-e868.

Wood, R. G., \& Rangarajan, A. (2005). The benefits of housing subsidies for TANF recipients: Evidence from New Jersey. http://www.mathematica-pr.com/*/media/publications/PDFs/wfnjhousing.pdf

Wood, D. L., Valdez, R. B., Hayashi, T., \& Shen, A. (1990). Health of homeless children and housed, poor children. Pediatrics, 86(6), 858-866.

Zilanawala, A., \& Pilkauskas, N. V. (2012). Material hardship and child socioemotional behaviors: Differences by types of hardship, timing, and duration. Children and Youth Services Review, 34(4), $814-825$.

Ziliak, J. (2015). Why are so many Americans on food stamps? In J. Bartfeld, C. Gundersen, T. M. Smeeding, \& J. P. Ziliak (Eds.), SNAP matters: How food stamps affect health and well-being (pp. 18-48). Stanford, CA: Stanford University Press. 